\title{
ANTONIO CANDIDO LEITOR DA POESIA DE JOÃO CABRAL DE MELO NETO ${ }^{1}$
}

\author{
SIQUEIRA, Joelma Santana ${ }^{2}$
}

RESUMO: A proposta do trabalho é discutir a resenha crítica de Antonio Candido publicada na coluna "Notas de crítica literária", do jornal Folha da manhã, em 13/06/1943, sobre o primeiro livro de poesia do escritor João Cabral de Melo Neto, Pedra do sono (1942). Busca-se demonstrar como essa crítica, que tem sido de grande importância para a recepção da poesia cabralina, relaciona-se à apresentação de princípios do crítico, discutida no texto de abertura da referida coluna, intitulado "Notas de Crítica Literária - Ouverture" e publicado em 07/01/1943.

PALAVRAS-CHAVE: Crítica Literária; Antonio Candido, João Cabral de Melo Neto; Pedra do sono.

\section{ANTONIO CANDIDO AS A READER OF JOÃO CABRAL DE MELO NETO'S POETRY}

\begin{abstract}
The purpose of this work is to discuss Antonio Candido's review essay, published in his column "Literary Criticism", on the Folha da Manhã newspaper in 06/13/1943, about the first book published by the writer João Cabral de Melo Neto, Pedra do sono (1942). The aim is to demonstrate how this criticism, which has been of great importance to the cabralina poetry, is related to the critic's presentation of its own principles, discussed on the very first text that started the column, titled "Notes on Literary Criticism - Ouverture", published in 01/071943.
\end{abstract}

KEYWORDS: Literary Criticism; Antonio Candido, João Cabral de Melo Neto; Pedra do sono.

O crítico Antonio Candido nasceu em 1918 no Rio de Janeiro e passou a infância em Minas Gerais. Em 1942, obteve os graus de bacharel e licenciado em Ciências Sociais pela Faculdade de Filosofia, Ciências e Letras da Universidade de São Paulo, tendo atuado entre 1942 e 1958 como primeiro-assistente do professor Fernando Azevedo na cadeira de Sociologia II dessa

\footnotetext{
${ }^{1}$ Trabalho realizado com apoio da FAPEMIG ao processo APQ-02606-17, Edital 001/2017, Demanda Universal.

${ }^{2}$ Professora de Literatura Brasileira, Universidade Federal de Viçosa-UFV. E-mail: jandrausufv@gmail.com
} 
instituição. Como destacou Vinícius Dantas (2002, p. 387-8), aprovado em concurso para a cadeira de Literatura Brasileira da USP, em 1945, paralelamente à vida universitária, "foi crítico literário da revista Clima (1945-47) e dos jornais Folha da Manhã (1943-45) e Diário de S. Paulo (1945-47), assinando um rodapé semanal com o título 'Notas de crítica literária"”. De 1958 a 1960, foi professor de Literatura Brasileira da UNESP de Assis, retornando no final desse período para a Universidade de São Paulo "na condição de colaborador de Teoria Literária e Literatura Comparada". No exterior, foi professor associado de Literatura Brasileira na Universidade de Paris (1964-66) e professor visitante de Literatura Brasileira e Literatura Comparada na Universidade de Yale (1968). Ainda em relação à vida acadêmica, de 1976 a 1978, foi coordenador do Instituto de Estudos da Linguagem da UNICAMP. Em 1974, tornouse titular e, em 1978, aposentou-se. Seu trabalho intelectual engloba outros espaços além do universitário. Nesse sentido, Dantas destacou que Antonio Candido,

Em 1945, foi um dos fundadores da União Democrática Socialista, que no mesmo ano integrou-se à Esquerda Democrática, transformada em 1947 no Partido Socialista Brasileiro, de cujo jornal, Folha Socialista, foi um dos diretores. De 1948 a 1949 presidiu a Associação Brasileira de Escritores, Seção de São Paulo. Em 1956 elaborou o projeto do Suplemento Literário do jornal $O$ Estado de S. Paulo. A partir de 1958 exerceu diversas funções na Fundação Cinemateca Brasileira, inclusive a presidência, entre 1962-64. Entre 1973 e 1974, foi um dos dirigentes da revista Argumento, proibida no quarto número pelo regime militar. Membro fundador do Partido dos Trabalhadores em 1980, exerceu nele o cargo de presidente do Conselho da Fundação Wilson Pinheiro e foi, por pouco tempo, encarregado do setor de Cultura do Governo Paralelo. Atualmente [2002] é presidente do conselho editorial da Fundação Perseu Abramo (DANTAS, 2002, p. 388).

Observa-se que a atividade crítica de Antonio Candido teve início no contexto do Estado Novo (1937-1945), período de ditadura em que, como escreveu Boris Fausto (2006, p. 366), "no comando do Estado, o poder pessoal de Getúlio representava a instância decisiva nas relações fundamentais". Nesse contexto também se deu o processo de autonomização do campo literário brasileiro. A atividade crítica de Antonio Candido atravessou vários momentos importantes de nossa história política. No presente trabalho, fixaremos nossa atenção nos anos 
1940, período que, de acordo com Randal Johnson (1995, p. 179), "marca o verdadeiro começo dos estudos sistemáticos de literatura brasileira no país".

No texto de abertura da coluna iniciada em 1943 no jornal Folha da Manhã com o título "Notas de Crítica Literária - Ouverture", publicado em 07 de janeiro de 1943, Antonio Candido faz a sua apresentação de princípios, algo que, de acordo com Dantas, era usual na época, quase mesmo obrigatório. Inicia o texto propondo que a primeira coisa que se deve esperar do crítico é sua definição de crítica, o que, por sua vez, leva ao "aspecto ético do seu ofício", ressaltando a importância de o leitor sentir-se diante de um "homem de boa-fé". Demonstrando modéstia e sinceridade, posto que, como informa, não irá expor "uma teoria que não tenho - nem uma ética - à qual não se faz jus num artigo inicial", apresentará "uma ou outra questão, um ou outro ponto de vista", a funcionar como "nota promissória" assinada por ele e direcionada ao leitor, que depois poderá cobrá-la do crítico.

Apesar da modéstia, o texto apresenta um posicionamento seguro do crítico em face da crítica contemporânea, opondo-se tanto à crítica impressionista quanto à crítica dita científica. Embora declare que não irá apresentar uma teoria, ao longo da leitura desse texto, é possível observarmos alguns pressupostos essenciais ao trabalho do crítico: o mergulho na obra a fim de intuir seus valores; a recusa a adoção de um método científico previamente fixado para a análise da obra literária, tanto quando a recusa à crítica impressionista; a busca pela significação da obra e o posicionamento do crítico fase ao que a obra propõe; o respeito aos limites do crítico, esse "escritor que passa"; a ascese que libera o crítico de simpatias pessoais e compadrios, mas também de antipatias e inimizades; e, por fim, "o dever de nada enunciar que não seja única e exclusivamente aquilo que lhe pareça a verdade”.

Esses pressupostos são coerentes com o que Antonio Candido enunciou sobre o primeiro livro de poesia de João Cabral de Melo Neto, Pedra do sono (1942), na resenha "Notas de crítica literária - Poesia ao Norte", publicado na Folha da Manhã em 13 de junho de 1943, portanto, cinco meses depois do texto de abertura da coluna.

A resenha aborda dois livros que o crítico diz ter em mãos: Pedra do Sono, de João Cabral, de Recife; e Anjos dos Abismos, de Rui Guilherme, de Óbidos, Pará. Desde o início, o destaque é dado ao primeiro como "poeta que já se apresenta de posse dos meios pessoais de expressão", enquanto o segundo "ainda se encontra preso demais à imitação". Consequentemente, o crítico se detém com mais vagar na obra de Cabral.

Ao destacar a epígrafe extraída de Mallarmé, observa as "imagens livremente associadas", presente na poesia de Cabral, propondo que, sobre essas, "o autor age como 
ordenador". Pedra do sono "é a obra de um poeta extremamente consciente que procura construir um mundo fechado para a sua emoção". São poemas "construídos com rigor, dispondo-se os seus elementos segundo um critério seletivo, em que se nota a ordenação vigorosa". Duas características são apontadas como principais: o hermetismo e a valorização plástica das palavras. Para Candido, Cabral, diante da matéria do sono e da associação livre, tinha "necessidade de certo rigor por assim dizer construtivista". Observa que há "um mínimo de matéria discursiva e um máximo de liberação do vocábulo". As palavras, dispostas "quase como valores plásticos", não constituem uma poesia racionalista, pois o trabalho ordenador "se exerce sobre os dados mais espontâneos da sensibilidade". Mais uma vez, ressalta a tendência construtivista, observando a pouca discursividade, que, por sua vez, estava presente nos versos de "Canção da moça-fantasma de Belo Horizonte", poema de Carlos Drummond de Andrade, publicado na obra Sentimento do Mundo, lançada há pouco, em 1940. Considera que, nos poemas de João Cabral, "não há sequência verbal”, são, em certo sentido, “estereogramas poéticos". O poema destacado por Candido é "Dentro da perda da memória", considerado um dos mais belos e exemplar das características apontadas na resenha, observando "o valor dominante que os substantivos exprimindo coisas passam a adquirir, ao lado das imagens por eles formadas".

Os grifos acima em algumas expressões de Antonio Candido têm a finalidade de ressaltar que muitas de suas observações dialogam com a recepção que a obra cabralina teve posteriormente. Nesse sentido, relembro o texto "O geômetra engajado", conferência pronunciada por Haroldo de Campos, em 1963, na Universidade do Rio Grande do Sul, no qual Campos (2004, p. 79) destaca que, em Pedra do Sono, "já se encontram em germe algumas das qualidades da poesia cabralina", citando como exemplos “o despojamento, o gosto pela imagem visual, de táctil substantividade...”. Marta Peixoto (1983, p. 10), na introdução do livro Poesia com coisas - uma leitura de João Cabral de Melo Neto, originalmente sua tese de doutorado, defendida na Universidade de Princeton, em 1977, escreveu que

Na crítica da obra de Cabral, que já conta com numerosos artigos e vários livros, alguns de grande valor, um comentário sobre o uso de palavras de referência concreta não é novidade. Já em 1943 Antonio Candido, em artigo sobre Pedra do sono, assinala o papel preponderante dos 'substantivos exprimindo coisas' e a 'tendência vamos dizer construtivista' de sua poesia. 
Este aspecto da obra cabralina foi depois retomado e elaborado em contextos diversos pelos principais estudiosos do poeta (PEIXOTO, 1983, p. 10).

Um dos aspectos mais conhecidos da resenha de Candido pelos estudiosos da poesia de Cabral é relação que o crítico estabelece entre o cubismo e o surrealismo tendo em vista o aspecto construtivo: "Não o chamo, porém, de cubista, porque ele não é só isso. O seu cubismo de construção é sobrevoado por um senso surrealista de poesia”. O cubismo e o surrealismo comparecem de modo mais explícito em dois poemas de Pedra do sono: "Homenagem a Picasso" e "A André Masson”. Cabral, muitas vezes, endossou a resenha crítica de Antonio Candido, a exemplo de quando, durante entrevista a Solena Benevides Vianna, publicada em O jornal, em 24. Fev. 1946, comentou que Pedra do sono teve como ponto de partida "um tratamento da imagem como tal" e que "o Sr. Antonio Candido teve, assim, toda razão quando salientou a importância do trabalho de construção desses poemas aparentemente, e para muita gente, supra-realista" (MELO NETO apud Mamede, 1987, p. 130). Em outra entrevista publicada em 1975 e concedida a Adalberto de Oliveira Souza e Maria Neuza Cardos, Cabral comentou mais detidamente a resenha de Antonio Candido:

...quando o meu primeiro livro saiu, eu estava no Recife. Eu conhecia do Antonio Candido de nome, ele já morava em S. Paulo e já fazia crítica literária. Eu mandei para ele o livro 'Pedra do Sono' sobre o qual ele publicou uma crítica no jornal 'Folha da Manhã' [...] Mas eu lá do Recife nem sabia da existência deste jornal - Folha da Manhã e não tinha lido esse artigo. Quando eu vim para o Rio, um dia conversando com o Carlos Drummond ele citou esse artigo de A. Candido. Hoje eu poderia colocá-lo como prefácio em minhas poesias completas porque ele previu tudo o que eu ia escrever, a maneira como eu ia escrever e meu primeiro livro não é ainda muito característico de minha maneira posterior, mas ele pressentiu tudo. Notou que minha poesia aparentemente surrealista, no fundo era poesia de um cubista. De fato, de todas as escolas, estilos de pintura, a coisa que mais me influenciou, mais me marcou foi o cubismo. Daí também essa grande influência de Le Corbusier. O Antonio Candido previu esse meu construtivismo, essa minha preocupação de compor o poema, de não deixar que o poema se fizesse sozinho, de falar das coisas e não de mim [...] (MELO NETO, apud MAMEDE, 1987, p. 150-1). 
O reconhecimento de Cabral à crítica de Antonio Candido é bastante preciso, mas devemos observar o fato de que sua poesia não se fixou em uma maneira de fazer. Cabral é um poeta inconformado no sentido de ter, constantemente, se mostrado insatisfeito com as soluções encontradas para sua obra. Mais de uma vez, despediu-se da poesia, como declarou na entrevista a Moacir Amâncio: "Eu tento me despedir há muito tempo. Em 1950, quando eu tinha 30 anos, eu entendia que seria a despedida, que não escreveria mais poesia”, mas foi quando, como sabemos, Cabral deu a lume $O$ cão sem plumas, responsável por outro momento de sua obra.

$\mathrm{Na}$ resenha, referindo-se ao poema "Homenagem a Picasso", Candido destacou a impressão de que o poeta estava "despoetizando demais as suas poesias, e fazendo uma natureza-morta, ou qualquer outra composição pictórica". Essa tendência "leva-o frequentemente ao exagero de um certo composicionismo verbal a que ele não sabe fugir", mas o crítico não sabia dizer se esse aspecto era devido ao "ar experimental" ou ao "caráter de primeira expedição literária desse livrinho de moço". A riqueza desses poemas, "de uma incontestável solução pessoal", por outro lado, tinha, para Candido, "um certo empobrecimento humano", propondo que "como Mallarmé, o poeta pernambucano se atirou em busca da poesia pura" e "toda pureza implica um aspecto de desumanização". Candido reclamava do risco de incomunicabilidade na poesia de Cabral. Depois de ter se detido na análise da linguagem poética, de ter mergulhado na obra, encerrava sua crítica intuindo sobre "seus valores", conforme propôs no texto de abertura da coluna "Notas de crítica literária". Suas últimas palavras sobre Pedra do sono foram:

Poesia assim tão autonomamente construída se isola no seu hermetismo. Aparece como um cúmulo de individualismo, de personalismo narcisista que, no sr. Cabral de Melo, tem um inegável encanto, uma vez que ele está na idade dessa espontaneidade na autocontemplação. O sr. Cabral de Melo, porém, há de aprender os caminhos da vida e perceber que lhe será preciso o trabalho de olhar um pouco a roda de si, para elevar a pureza da sua emoção a valor corrente entre os homens e, desse modo, justificar a sua qualidade de artista (CANDIDO, apud Dantas, 2002, p. 141).

Observa-se, portanto, por parte do leitor Antonio Candido um posicionamento sobre a significação geral da obra, entendendo por tal coisa, como escreveu no artigo de abertura, "o 
sistema de relações que a prendem ao seu momento e a posição dele, leitor, ante ambos". Explicando melhor, esclarece-nos que se trata de

\begin{abstract}
procurar tirar da obra, graças à compreensão dos seus liames com o tempo, a inteligência deste e uma orientação para a conduta. Interpretar a obra, numa palavra, em vista do que ela pode ter de explicativo do seu momento. Aliás, no nosso tempo, essa atitude se impõe. Não depende da boa ou má vontade do leitor, da maior ou menor habilidade do autor; é uma imposição como muitas outras a que não podemos nos esquivar (Idem, 26).
\end{abstract}

Como dissemos antes, era tempo de ditadura. No dia 30 de abril de 1942, Antonio Candido esteve na audiência da conferência "O movimento modernista”, de Mário de Andrade (1942, p. 74) na qual o famoso escritor fez uma avaliação severa do movimento, destacando "uma antiquada ausência de realidade" em sua obra e na de muitos de seus contemporâneos: "Viramos abstencionistas abstêmicos e transcendentes". Devemos lembrar, como o fez Jason Tércio (2019, p. 453), que "essa autocrítica de Mário deve ser relativizada, era um reflexo do contexto político no Brasil em 1942”, e, nesse sentido, lembrar também que, embora sutis, as palavras de Antonio Candido, em 1943, têm efeito semelhante.

João Cabral não se esquivou de seu tempo. Antes da publicação da resenha de Candido, conforme escreveu em uma correspondência de 23/11/1941 para o poeta Carlos Drummond de Andrade, quando lhe enviava uma cópia de Pedra do sono, desejou ter realizado uma poesia diferente: "Sinto que não é esta a poesia que eu gostaria de escrever; o que eu gostaria é de falar numa linguagem mais compreensível desse mundo de que os jornais nos dão notícias todos os dias, cujo barulho chega até a nossa porta; uma coisa menos 'cubista"' (Apud SUSSEKIND, 2001, p. 171).

Podemos perceber em seus versos sintomas da incompreensão do mundo em tempo de guerra. Concordando em muitos aspectos com a resenha crítica de Antonio Candido, o poeta não se limitou a fixar-se nas soluções empregadas em seu primeiro livro. No ensaio “Linguagem e metalinguagem em João Cabral”, João Alexandre Barbosa (1974, p. 139) considerou-o poeta cuja "'leitura' da realidade parece ser crítica na medida em que submete os termos através dos quais ela se realiza a um permanente discurso de indagação acerca de seus relacionamentos".

Muitas vezes, Cabral se opôs à poesia intimista, centrada no eu, confessional. No texto “Da função moderna da poesia", apresentado no Congresso de Poesia de São Paulo, em 1954, 
defendeu a função comunicativa da poesia, observando, por exemplo, que escrever deixou de ser para determinados poetas modernos "atividade transitiva de dizer determinadas coisas a determinadas classes de pessoas; escrever é agora atividade intransitiva, é, para esse poeta, conhecer-se, examinar-se, dar-se em espetáculo; é dizer uma coisa a quem puder entendê-la ou interessar-se por ela" (CABRAL, 2003, p. 768).

Essa passagem exemplifica, conforme observamos no artigo "João Cabral na imprensa brasileira nos anos 1950", outro momento de procura e crítica do poeta, mais interessado em uma poesia que trabalhe o tema dos homens, atenta às mazelas sociais e à comunicação com esses mesmos homens. A crítica de Antonio Candido ao primeiro livro de João Cabral, endossada muitas vezes pelo próprio escritor, dá início a uma direção na recepção da obra cabralina que enfatiza sobretudo o rigor construtivo de seus versos, e cobrava do escritor o envolvimento com a realidade social, algo também visado pelo poeta pernambucano.

Em outros momentos, Antonio Candido voltou a escrever sobre a poesia de João Cabral. No artigo "Poeta e poetisa", publicado no Diário de São Paulo, em 1945, comenta sobre a obra $O$ engenheiro, considerando que Cabral, "libertando-se da experimentação preliminar, realizou "uma aventura lírica muito mais significativa" (CANDIDO apud Mamede, 1987, p. 289). Em 1964, Antonio Candido e Aderaldo Castelo publicaram a primeira edição do volume Presença da literatura brasileira. Na $14^{\text {a }}$ edição dessa obra, publicada em 2005, lemos que a obra de João Cabral, "em pleno desenvolvimento, é um exemplo raro de rigor formal e pureza expressiva, ligados a uma forte visão dos problemas humanos, que chega à tomada de posição social" (CANDIDO; CASTELLO, 2005, p. 36).

Em 1967, publicou na revista portuguesa O tempo e o modo, o texto "Movimento geral da literatura contemporânea" em que observa um mecanismo de "afinidades profundas" entre a poesia de João Cabral e "certos modos da poesia popular da sua região nordestina". Até essa data, Cabral tinha publicado, além de Pedra do sono (1941); Os três mal amados (1943); $O$ engenheiro (1945); O cão sem plumas (1950); O Rio (1953); Duas águas (1956), contendo livros anteriores e os inéditos "Morte e vida Severina", "Paisagem com figuras" e "Uma faca só lâmina"; Quaderna (1960); Terceira feira (1961), e A educação pela pedra (1966). A primeira edição das Poesias completas foi publicada em 1968. Nesse ano, no livro Introducción a la literatura de Brasil (1968), Candido escreveu que na obra de Cabral se encontra "de um lado, el limite extremo de la pureza, em um esfuerzo por reducir al mínimo possible el elemento discursivo; de otro, la presencia de la participación humana, como sentido de la poesia em el mundo" (CANDIDO, apud Mamede, 1987, p. 201). Em textos críticos 
posteriores de Antonio Candido sobre a poesia cabralina é possível identificar diálogo com sua primeira resenha à obra Pedra do sono.

No texto "O ideal do crítico", publicado primeiramente no Diário do Rio de Janeiro, em 8 de outubro de 1865, Machado de Assis (2011, p. 7-8), após destacar que, entre nós, eram "raras as publicações seladas por um talento verdadeiro", destacou que, para mudar essa situação, era preciso estabelecer

A crítica, mas a crítica fecunda, e não a estéril, que nos aborrece e nos mata, que não reflete nem discute, que abate pro capricho ou levanta por vaidade; estabelecei a crítica pensadora, sincera, perseverante, elevada - será esse o meio de reerguer os ânimos, promover os estímulos, guiar os estreantes, corrigir os talentos feitos; condenai o ódio, a camaradagem e a indiferença essas três chagas da crítica de hoje - ponde em lugar deles a sinceridade, a solicitude e a justiça - é só assim que teremos uma grande literatura (ASSIS, 2011, p. 8).

Antonio Candido realizou a crítica fecunda de que fala Machado de Assis, ciente, como escreveu em seu texto de abertura, de que o crítico não dispõe de nenhuma "faculdade extraordinária" para realizar o seu trabalho, "a interpretação da obra devendo se basear na busca daquilo que, nela, representa a parte mais significativamente ligada ao espírito da sua época". Seu texto de abertura da coluna "Notas de crítica literária", assim como a resenha crítica sobre Pedra do Sono e essa primeira obra de João Cabral foram publicadas durante o contexto do Estado Novo. Nesse período, Antonio Candido integrou a Frente de Resistência contra a ditadura e, participou da fundação da União Democrática Socialista. Escreveu em seu texto de abertura da coluna que "o crítico é, por excelência, o escritor que passa, que mais rapidamente envelhece; e a sua missão estará cumprida se puder ter contribuído para orientar os seus contemporâneos". Encerrava destacando que "se nem sempre é possível dizer tudo aquilo que se pensa, é sempre possível dizer apenas aquilo que se pensa. E é o que farei”. Diante de tais palavras e do que vimos tentando demonstrar nesse trabalho, encerramos esse breve texto observando que Antonio Candido foi um crítico que, ao passar, deixou contribuições que foram importantes para o escritor João Cabral e seus leitores. A crítica do saudoso estudioso da literatura segue passando com relevância para as futuras gerações de escritores, de críticos, de leitores. 


\section{REFERÊNCIAS BIBLIOGRÁFICAS}

ANDRADE, Mário de. O movimento modernista. Rio de Janeiro: Edição Casa do Estudante do Brasil, 1942.

ASSIS, Machado de. "O ideal do crítico". In: O jornal e o livro. São Paulo: Companhia das Letras, 2011.

FAUSTO, Boris. História do Brasil. São Paulo: Editora da Universidade de São Paulo, 2006. BARBOSA, João Alexandre. "Linguagem \& metalinguagem em João Cabral”. In: A metáfora crítica. São Paulo: Perspectiva, 1974.

CAMPOS, Haroldo. "O Geômetra engajado". In: Metalinguagem e outras metas. São Paulo: Perspectiva, 2004.

CANDIDO, Antonio. "Notas de crítica literária - Ouverture". In: Textos de intervenção. São Paulo: Editora 34, 2002.

CANDIDO, Antonio. "Notas de crítica literária - Poesia ao Norte". In: Textos de intervenção. São Paulo: Editora 34, 2002.

CANDIDO, Antonio; CASTELLO, José Aderaldo. Presença da literatura brasileira: história e crítica. II Modernismo, 14. ed. Rio de Janeiro: Bertrand Brasil, 2005.

CANDIDO, Antonio. Textos de intervenção/Antonio Candido. Seleção, apresentação e notas de Vinícius Dantas. São Paulo: Duas cidades, Ed. 34, 2002.

DANTAS, Vinícius. Bibliografia de Antonio Candido. São Paulo: Duas cidades, Ed. 34, 2002. MAMEDE, Zilá. Civil geometria. Bibliografia crítica, analítica e anotada de João Cabral de Melo Neto 1942-1982. São Paulo: Nobel, 1987.

MELO NETO, João Cabral. [Entrevista] O Estado de S. Paulo, 19 jan 1986. Entrevista a Moacir Amâncio

MELO NETO, João Cabral. Obra completa. Rio de Janeiro: Nova Aguilar, 1994.

PEIXOTO, Marta. Poesia com Coisas: uma leitura de João Cabral de Melo Neto. São Paulo: Perspectiva, 1983.

JOHNSON, Randal. “A dinâmica do campo literário brasileiro (1930-1945)". Trad. Antônio Dimas. Revista USP. n. 26. São Paulo, jun/jul/ago, 1995.

Disponível em $<$ http://www.revistas.usp.br/revusp/article/view/28160>. Último acesso em 18 de outubro de 2015. SIQUEIRA, Joelma Santana. "João Cabral de Melo Neto na imprensa brasileira nos anos 1950".

Revista Texto poético. v. 14, n. 25, 2018. Disponível em < http://revistatextopoetico.com.br/index.php/rtp/article/view/532/392> Último acesso em 11 mar. 2019.

SÜSSEKIND, Flora. Correspondência de Cabral com Bandeira e Drummond. Rio de Janeiro: Nova Fronteira, 2001.

TÉRCIO, Jason. Em busca da alma brasileira: biografia de Mário de Andrade. Rio de Janeiro: Estação Brasil, 2019. 